\title{
Design and Performance Characteristics of the ORNL Advanced Microscopy Laboratory and JEOL 2200FS-AC Aberration-Corrected STEM/TEM
}

\author{
L.F. Allard,* D.A. Blom, ${ }^{*}$ M.A. O’Keefe, ${ }^{* *}$ and S. Mishina*** \\ *Metals and Ceramics Division, Oak Ridge National Laboratory, Oak Ridge, TN 37831-6064, USA \\ **Materials Sciences Division, LBNL 2-200, Berkeley, CA 94720, USA \\ ***JEOL USA Ltd., 11 Dearborn Rd., Peabody, MA 01960, USA
}

To achieve the highest performance with today's generation of aberration-corrected electron microscopes, it is increasingly evident that the environment of the facility in which the microscope is installed must be considered an integral component of the microscopy program. Such instruments are the world's best detectors of the influence of parameters such as alternating magnetic fields, floor vibrations, acoustic vibrations, airflow, and temperature and pressure fluctuations [1]. At ORNL, the new Advanced Microscopy Laboratory (AML) has recently been completed, with two aberration-corrected instruments installed, and two more planned in the near future to fill the 4laboratory building. Design criteria for the facility include the following: magnetic fields below $0.1 \mathrm{mG} \mathrm{rms} \mathrm{in} \mathrm{all} \mathrm{directions,} \mathrm{floor} \mathrm{vibrations} \mathrm{below} 1 \mu \mathrm{m} / \mathrm{sec}$, air flow less than $5 \mathrm{~cm} / \mathrm{sec}$ horizontally, temperature stability $\pm 0.2^{\circ} \mathrm{C} / \mathrm{hr}$, and provision for instrument operation from an adjacent control room to minimize the influence of the operator on instrument performance. Figure 1 shows the completed AML. The mechanical building (in front) contains all HVAC equipment and instrument water chillers, and is physically isolated from the high bay instrument building. All electrical wiring is twisted to mitigate fields. Details of the building design are given in Ref. 1. Figure 2 shows the interior of the control room, looking toward the column through a window into the instrument room. Figure 3 is a cross section through the instrument room, illustrating the supply and return of air. Cold air is dumped into a mixing plenum above a perforated, sound-insulated drop ceiling, so that it flows into the instrument room over the entire ceiling area. The air is returned through plenums formed by false walls on two sides of the room, with openings at floor level extending the full length of the room. Even with 11 changes of air per hour, the maximum velocity from ceiling to floor is less than $5 \mathrm{~cm} / \mathrm{sec}$, and horizontal flow rate via convection is even lower. Temperature stability is within $\pm 0.1^{\circ} \mathrm{F} / \mathrm{hr}$. Magnetic fields in all instrument rooms ranged from 0.2 to $0.5 \mathrm{mG}$. In like fashion, floor vibrations were below $1 \mu \mathrm{m} / \mathrm{sec}$ throughout the low frequency regime. These and other design parameters effectively provide an excellent environment for operation of our sub- $\AA$ microscopes.

The JEOL 2200FS-AC, being installed as of this writing, has demonstrated a TEM information limit of $0.9 \AA$ [2]. This is the limit expected given the measured instrument parameters (HT and OL power supply stabilities, beam energy spread, etc.), and illustrates that the environmental influences are not adversely affecting the instrument performance. However, in STEM high-angle annular dark-field (HA-ADF) mode, images of a thin Si crystal in $<110>$ zone axis orientation, after primary aberrations in the illuminating beam were optimally corrected, showed a significant vibration effect. Figure 4a shows a Si atomic column image and its diffractogram with this vibration. Holographylike "sidebands" in the diffractogram are produced by an $800 \mathrm{~Hz}$ signal. The microscope is fitted with three magnetically levitated turbo pumps (one on the column at about the specimen position, and two near floor level) that pump the Omega energy filter and detector chamber. These pumps run at $48,000 \mathrm{rpm}$, precisely equivalent to $800 \mathrm{~Hz}$. It was determined that the upper turbo pump was contributing essentially all of the $800 \mathrm{~Hz}$ signal to the image, and in fact that the pump was defective. After replacing the pump with one significantly quieter than the original, the Si atomic column image and associated diffractogram (Fig. 4b) show a much-reduced effect of the $800 \mathrm{~Hz}$ signal, but still some residual effect from the turbo pump. The upper pump will be removed from the main column to an adjacent frame on the floor, and will have a large-diameter, well-damped, pump line to the original connection to the column to effectively isolate the pump from the column. If the $800 \mathrm{~Hz}$ signal results from mechanical vibrations, they will be damped, and if the signal results from acoustic coupling to the column, it can be damped by appropriate acoustic materials. The effectiveness of this solution on the resolution of the instrument in HA-ADF mode will be reported [3]. 
[1] M. A. O'Keefe et al., Microscopy Today 12 (Issue 3 - May) (2004) 8-14.

[2] D. A. Blom, L. F. Allard, M. A. O’Keefe and S. Mishina, these Proceedings.

[3] Research sponsored by Assistant Secretary for Energy Efficiency and Renewable Energy, Office of FreedomCAR and Vehicle Technologies, U.S. Department of Energy (DOE), as part of the HTML User Program, ORNL, managed by UT-Battelle, LLC for the U.S. DOE under contract DEAC05-00OR22725. Additional sponsorship [MAOK] from the Director, Office of Science, Office of Basic Energy Sciences, Materials Science Division, U.S. DOE, under contract DE-AC03$76 \mathrm{SF} 00098$.
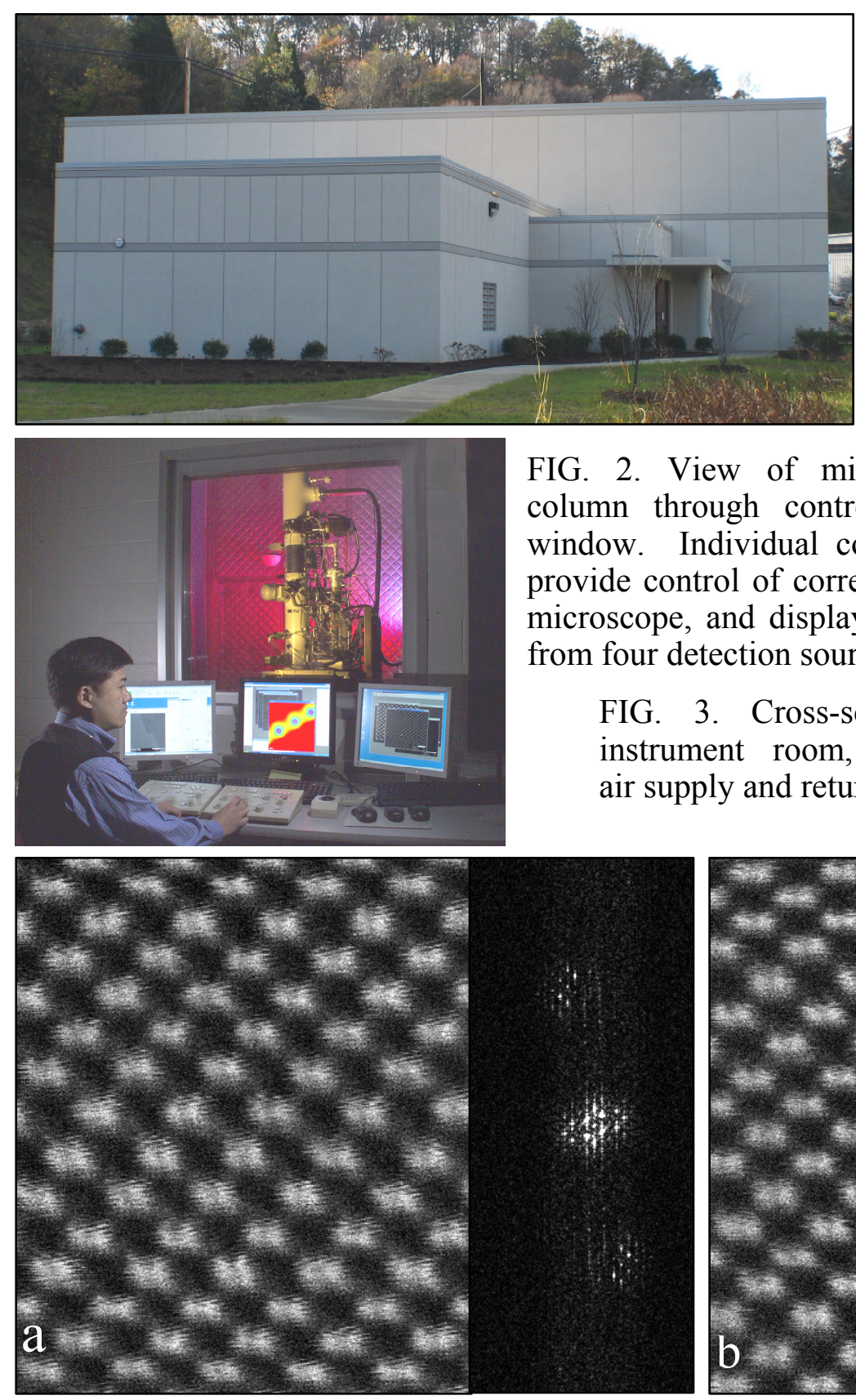
from four detection sources.
FIG. 1. View of Advanced Microscopy Laboratory at ORNL. The low building in front houses HVAC units, electrical distribution, and instrument water chillers, while the high building houses microscope and associated control rooms. Power to the instruments is supplied by a motor-generator set, housed in the adjacent High Temperature Materials Laboratory (HTML).

FIG. 2. View of microscope column through control room window. Individual computers provide control of corrector and microscope, and display images

FIG. 3. Cross-section of instrument room, showing air supply and return pattern.
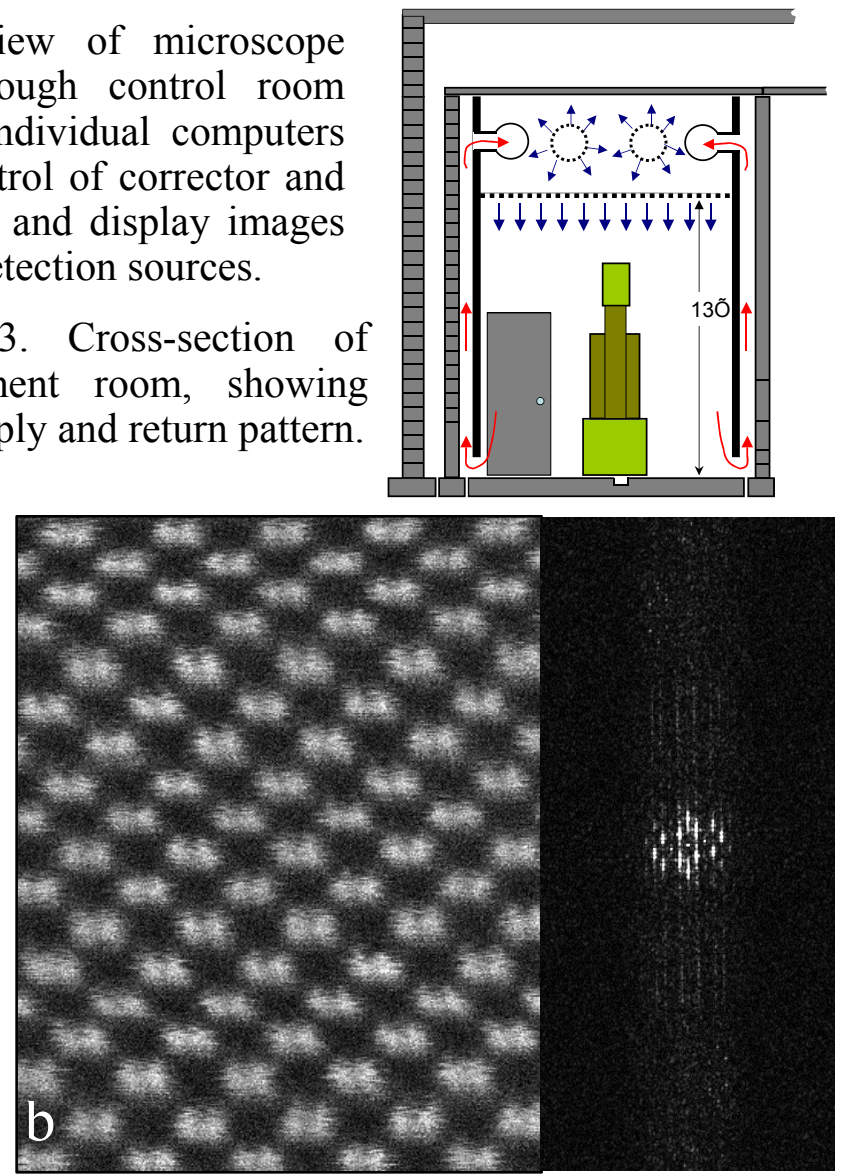

FIG. 4. Si $<110>$ lattice showing $1.36 \AA$ dumbbells, and corresponding diffractogram: a) with $800 \mathrm{~Hz}$ signal from upper turbo pump; b) after exchanging turbo pumps. Note the significant reduction in the diffractogram "sidebands" related to the periodic $800 \mathrm{~Hz}$ disturbance. 